\section{Three New Early Flowering Iris germanica Cultivars}

\author{
Yongxia Zhang, Qingquan Liu, Yinjie Wang, Yongheng Yang, \\ Ting Zhang, and Haiying Tong \\ Institute of Botany, Jiangsu Province and Chinese Academy of Sciences, \\ Nanjing, 210014, China

\section{Wenjie An \\ Shanxi Forestry Vocational Technical College, Taiyuan, 030009, China}

\section{Suzhen Huang and Haiyan Yuan \\ Institute of Botany, Jiangsu Province and Chinese Academy of Sciences, Nanjing, 210014, China}

Iris is the largest genus of the Iridaceae (Asparagales), which includes more than 300 species with diverse growing habitats. Most of them are found in desert, semidesert, dry, or rocky habitats, and only few occur in wetland environments (Kaššák, 2012). There are abundant Iris resources in China, and $\approx 60$ Iris species are widely distributed in the northwest, northeast, and southwest of China (Deng et al., 2009). Iris germanica L. belongs to Iris genus and is the most extensively cultivated species of Iridaceae and spread mostly across the northern temperate zone (Kohlein, 1987; Mitra, 1956). They are well known for their singular flower type and plentiful rainbow-like flower color. The showy appearance and convenient cultivation and propagation contribute to the extraordinary prevalence of $I$. germanica L. globally (Fan et al., 2020; Zhao et al., 2016). However, I. germanica has a relatively short flowering period that is concentrated in April for most cultivars in China. To extend the flowering period, we released three new $I$. germanica cultivars, Autumnal Moon, Purple Canary, and Butter Baby, in 2019 that were characterized by attractive flowers and blooming in the early March. They belong to the Standard Dwarf Bearded (SDB) of $I$. germanica.

'Purple Canary' and 'Butter Baby' were selected from the cross 'Sun Doll' $\times$ '00244' and '00246' × '00267', respectively, and 'Autumnal Moon' was selected from an

\footnotetext{
Received for publication 8 June 2020. Accepted for publication 10 July 2020.

Published online 13 August 2020.

The work was supported by the National Natural Science Foundation of China (31801901), the Natural Science Foundation of Jiangsu (BK20180314), the Foundation of Key Laboratory of Landscaping (KF201901), Ministry of Agriculture and Rural Affairs, P.R. China, and the Jiangsu Key Laboratory for the Research and Utilization of Plant Resources (JSPKLB201814).

H.Y. is the corresponding author. E-mail: yuanhaiyan416@ 163.com.

This is an open access article distributed under the CC BY-NC-ND license (https://creativecommons. org/licenses/by-nc-nd/4.0/).
}

open-pollinated progeny population of 'Blueberry Tart' at Iris Germplasm Repository in Institute of Botany, Jiangsu Province and Chinese Academy of Sciences. 'Sun Doll', '00244', '00246', '00267', and 'Blueberry Tart' were introduced from Xi' an Botanical Garden of China in 1997. The hybridizations between 'Sun Doll' $\times$ '00244', '00267' $\times$ were conducted in 2012. In 2014, three excellent individuals were obtained from their respective progeny population, which belong to the Standard Dwarf Bearded (SDB) iris. From 2014 to 2016, individuals were propagated by tissue culture and observed continuously from 2017 to 2019. Field performances in Nanjing, Lishui, and Dongtai suggested that all three lines show earlier flowering time compared with their parents and exhibit stable morphologies. The new cultivars were officially authorized to be released as Autumnal Moon, Purple Canary, and Butter Baby by the American Iris Society in 2019 (accession nos. 19-1004, 19-1005, and 19-1006).

\section{Description}

The three new cultivars and their parents were planted at the Iris Germplasm Repository, Institute of Botany, Jiangsu Province, and the Chinese Academy of Sciences for data collection from 2017 to 2019. Each cultivar and its parent plants were arranged in a randomized experiment of 30 plants (three replications $\times 10$ plants in each replication). Morphological characteristics including plant height, leaf length, leaf width, flower length, flower width, flower length/ width, inner perianth length, inner perianth width, inner perianth length/width, outer perianth length, outer perianth width, outer perianth length/width, and flowering period were investigated and analyzed by one-way analysis of variance and independentsamples $t$ test using IBM SPSS Statistics 19 software.

The plant height of 'Autumnal Moon' is $27.94 \mathrm{~cm}$, which is close to 'Blueberry Tart' $(24.4 \mathrm{~cm})$. 'Autumnal Moon' and 'Blueberry Tart' are similar in leaf length; however, the '00246', and 'Blueberry Tart' $\times$ unknown leaf width of 'Autumnal Moon' is less than 'Blueberry Tart' (Table 1). In addition, the outer and inner perianth color of 'Autumnal Moon' is blue (RHS 97A), in contrast to the blue inner perianth (RHS 101C) and dark orange yellow outer perianth (RHS 22A) of 'Blueberry Tart'. Moreover, the beard top color of 'Autumnal Moon' is white (RHS 97C) compared with the blue beard top (RHS 101C) of 'Blueberry Tart' (Fig. 1A and B). The flower width of 'Autumnal Moon' is similar to 'Blueberry Tart', whereas the flower length and flower length/width are less than 'Blueberry Tart'. The flowering season of 'Autumnal Moon' is from 10 Mar. to 25 Mar., which is similar to that of 'Blueberry Tart'.

The plant height of 'Purple Canary' is $30.48 \mathrm{~cm}$, which is shorter than those of the female parent 'Sun Doll' $(49.66 \mathrm{~cm})$ and male parent '00244' $(59.20 \mathrm{~cm})$. The leaf length of 'Purple Canary' is similar to 'Sun Doll' but shorter than '00244'. However, the leaf width of 'Purple Canary' is similar to '00244' but narrower than 'Sun Doll' (Table 1). The flower color of 'Purple Canary' is yellow (RHS 12A) and close to 'Sun Doll' (RHS 6A), in contrast to the violet color (RHS N87A) of '00244'. In addition, 'Purple Canary' has attractive beard with purple (RHS N82B) end and yellow (RHS 163A) in throat (Fig. 1C-E). The flower length (8.5 $\mathrm{cm}$ ) of 'Purple Canary' is similar to '00244' $(9.2 \mathrm{~cm})$ but less than 'Sun Doll' $(12.66 \mathrm{~cm})$. However, its flower width $(6.0 \mathrm{~cm})$ is less than both parents. The length, width, and length/width of inner and outer perianth of 'Purple Canary' are all between its parents (Table 1). The flowering time of 'Purple Canary' is from 12 Mar. to 2 Apr., earlier than both the female and male parents (flowering time from 29 Mar. to 23 Apr. and 20 Apr. to 10 May, respectively).

The plant height of 'Butter Baby' is 25.4 $\mathrm{cm}$, which is higher than '00267' $(19.38 \mathrm{~cm})$ but shorter than '00246' (62.44 cm). The leaf length and width of 'Butter Baby' are similar to female parent ('00267') but less than male parent ('00246') (Table 1). The yellow flower color (RHS 12A) of 'Butter Baby' is similar to '00246' (RHS 6A) but different from the light blue inner perianth (RHS 104D) and yellow brown outer perianth (RHS 167B) of '00267'. The beards color of 'Butter Baby' is white (RHS 155C), in contrast to the orange yellow (RHS14A) of '00246' and light blue (RHS 104D) of '00267' (Fig. 1F-H). The flower morphology of 'Butter Baby' is similar to the female parent ('00267') but distinct to its male parent ('00246'). Its flower length and width are smaller than '00246' but flower length/width is larger than ' 00246 '. The ratio of inner perianth length/width of 'Butter Baby' is greater than male parent; however, the outer perianth length/width is less than male parent. The outer perianths of 'Butter Baby' and its female parent are oval-like and open horizontally when blooming, compared with the drooped outer perianths of its male parent. The flowering period of 'Butter Baby' (10 Mar. to 28 Mar.) is similar to the female 


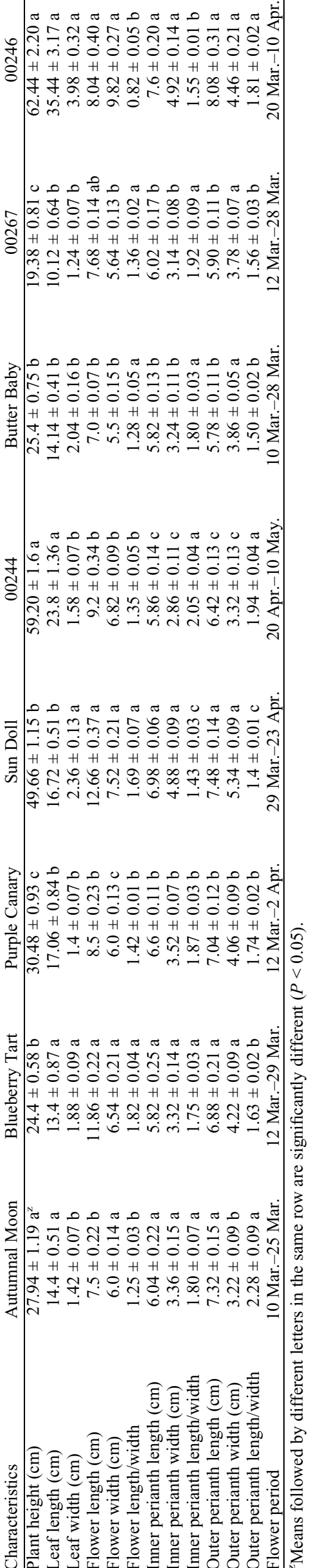

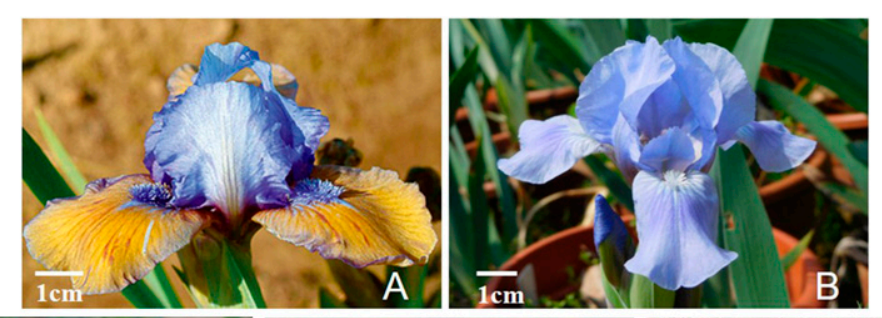
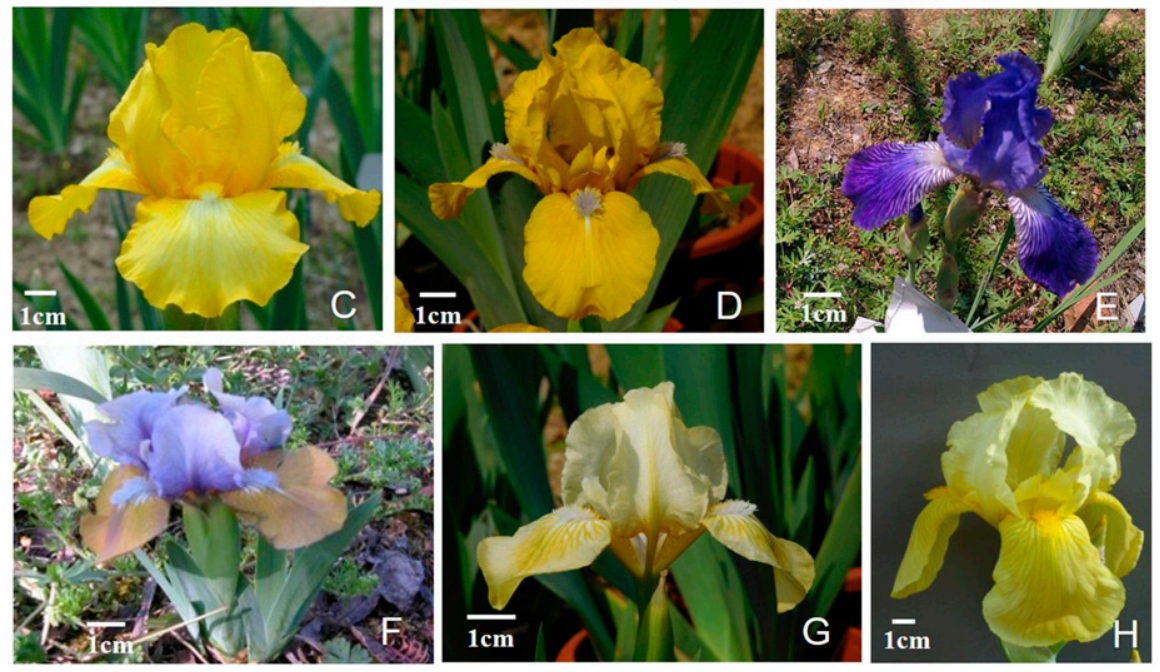

Fig. 1. Single flower of $I$. germanica 'Blueberry Tart' (A), 'Autumnal Moon' (B), 'Sun Doll' (C), 'Purple Canary' (D), '00244' (E), '00267' (F), 'Butter Baby' (G), and '00246' (H).

parent (12 Mar. to 28 Mar.) but slightly earlier than male parent (20 Mar. to 10 Apr.) (Table 1).

In short, 'Autumnal Moon', 'Purple Canary', and 'Butter Baby' all belong to the SDB of I. germanica. Compared with the intensive flowering time of most $I$. germanica in April, these three new cultivars could bring forward the flower blooming to early March, which greatly extends the flowering period of I. german$i c a$ as ornamental groundcover. In addition, due to the dwarfism of these new cultivars, they can be used as potted flowers in home decoration as well.

\section{Availability}

Information about plant materials and research of 'Autumnal Moon', 'Purple Canary', and 'Butter Baby' can be obtained from Dr. Hai-yan Yuan (e-mail: yuanhaiyan416@163.com) at the Institute of Botany, Jiangsu Province, and Chinese Academy of Sciences, Nanjing, China.

\section{Literature Cited}

Deng, G.B., H.B. Zhang, H.F. Xue, S.N. Chen, and X.L. Chen. 2009. Chemical composition and biological activities of essential oil from the rhizomes of Iris bulleyana. Agr. Sci. China 8:691-696.

Kaššák, P. 2012. Secondary metabolites of the chosen genus Iris species. Acta Univ. Agr. Silvic. Mendel. Brun. 60:269-280.

Fan, Z.P., Y.K. Gao, R. Liu, X.Z. Wang, Y.C. Guo, and Q.X. Zhang. 2020. The major gene and polygene effects of ornamental traits in bearded iris (Iris germanica) using joint segregation analysis. Scientia Hort. 260:108882.

Mitra, J. 1956. Karyotype analysis of Bearded Iris. Bot. Gaz. 117:265-293.

Kohlein, F. 1987. Iris. Timber Press, Portland, OR.

Zhao, X.J., G.H. Bi, R.L. Harkess, J.J. Varco, and E.K. Blythe. 2016. Spring nitrogen uptake, use efficiency, and partitioning for growth in Iris germanica 'Immortality'. HortScience 51:563566. 